\title{
Exploring the Role of IL-32 in HIV-Related Kaposi Sarcoma
}

George Semango, ${ }^{* \dagger}$ Bas Heinhuis, ${ }^{\ddagger \S}$ Theo S. Plantinga, ${ }^{\top}$ Willeke A.M. Blokx, ${ }^{\top}$ Gibson Kibiki,, Tolbert Sonda,, Daudi Mavura, ** Elisante J. Masenga, ${ }^{* *}$ Mramba Nyindo, ${ }^{*}$ Andre J.A.M. van der Ven, ${ }^{\ddagger \S}$ and Leo A.B. Joosten ${ }^{\ddagger \$}$

From the Kilimanjaro Christian Medical University College, $*$ Moshi, Tanzania; the School of Life Sciences, ${ }^{\dagger}$ Nelson Mandela African Institute of Science and Technology, Arusha, Tanzania; the Departments of Internal Medicine ${ }^{\ddagger}$ and Pathology and the Radboud Center of Infectious Diseases, ${ }^{\S}$ Radboud University Medical Centre, Nijmegen, the Netherlands; the Kilimanjaro Clinical Research Institute, "Moshi, Tanzania; and the Regional Dermatology Training Centre, ** Moshi, Tanzania

Accepted for publication August 23, 2017.

Address correspondence to George Semango, M.Sc., Nelson Mandela African Institute of Science and Technology, PO Box 447, Arusha, Tanzania. E-mail: george. semango@nm-aist.ac.tz.

\begin{abstract}
The intracellular proinflammatory mediator IL-32 is associated with tumor progression; however, the mechanisms remain unknown. We studied IL-32 mRNA expression as well as expression of other proinflammatory cytokines and mediators, including IL- $1 \alpha$, IL-1 $\beta$, IL- 6, IL- 8 , tumor necrosis factor (TNF)- $\alpha$, the proangiogenic and antiapoptotic enzyme cyclooxygenase-2, the IL- 8 receptor $\mathrm{C}-\mathrm{X}-\mathrm{C}$ chemokine receptor (CXCR) 1, and the intracellular kinase focal adhesion kinase-1. The interaction of IL-32 expression with expression of IL-6, TNF- $\alpha$, IL-8, and cyclooxygenase-2 was also investigated. Biopsy specimens of 11 HIV-related, 7 non-HIV-related Kaposi sarcoma (KS), and 7 normal skin tissues (NSTs) of Dutch origin were analyzed. RNA was isolated from the paraffin material, and gene expression levels of IL-32 $\alpha, \beta$, and $\gamma$ isoforms, IL1a, IL1b, IL6, IL8, TNFA, PTGS2, CXCR1, and PTK2 were determined using real-time quantitative PCR. Significantly higher expression of IL-32 $\beta$ and IL-32 $\gamma$ isoforms was observed in HIV-related KS biopsy specimens compared with non-HIV-related KS and NST. The splicing ratio of the IL-32 isoforms showed IL-32 $\gamma$ as the highest expressed isoform, followed by IL-32 $\beta$, in HIV-related KS cases compared with non-HIV-related KS and NST. Our data suggest a possible survival mechanism by the splicing of IL-32 $\gamma$ to IL-32 $\beta$ and also IL-6, IL-8, and CXCR1 signaling pathways to reverse the proapoptotic effect of the IL-32 $\gamma$ isoform, leading to tumor cell survival and thus favoring tumor progression. (Am J Pathol 2018, 188: 196-203; https://doi.org/10.1016/j.ajpath.2017.08.033)
\end{abstract}

IL-32 is a proinflammatory and proapoptotic cytokine that plays a role in carcinogenesis, ${ }^{1-3}$ inflammation, ${ }^{4}$ and host defense to infectious agents, such as HIV and Mycobacterium tuberculosis. ${ }^{5,6}$ IL-32 mRNA is preferentially expressed in immune cells. ${ }^{7}$ IL-32 induces production of proinflammatory cytokines, including tumor necrosis factor (TNF)- $\alpha$, IL-1 $\beta$, IL-6, and IL-8 via NF- $\mathrm{B}$, p38 mitogenactivated protein kinase, and activating protein-1 activation. $^{7}$ The sources of IL-32 include natural killer cells, T cells, monocytes, endothelial cells, and epithelial cells, ${ }^{8,9}$ with endothelial cells reported to exhibit the highest expression. Human IL-32 exists as six splice variants $(\alpha, \beta$, $\gamma, \delta, \varepsilon$, and $\zeta) .^{7}$ The most frequently found isoforms, however, are IL-32 $\alpha, \beta$, and $\gamma^{7}$ The IL-32 isoforms probably originate by splicing of pre-mRNA of the isoform $\mathrm{IL}-32 \gamma \cdot{ }^{10} \mathrm{IL}-32 \gamma$ is regarded as the most active isoform of the cytokine, whereas splicing of IL-32 $\gamma$ into IL-32 $\beta$ is thought to be a safety switch in controlling the effects of IL$32 \gamma$ and thereby reducing chronic inflammation. ${ }^{11}$

IL-32 is being extensively studied and has been implicated in several diseases, ranging from autoimmune disorders (eg, rheumatoid arthritis), ${ }^{12}$ to chronic obstructive pulmonary disease, ${ }^{13}$ and to infectious diseases (eg, HIV). ${ }^{6}$ More recently, it

\footnotetext{
Supported by the Department of Internal Medicine, Radboud University Medical Center (Nijmegen, the Netherlands; A.J.A.M.v.d.V. and L.A.B.J.) The HIV Research Trust supported part of travel costs to the Netherlands to work on the project (G.S.).

A.J.A.M.v.d.V. and L.A.B.J. contributed equally to this work as senior authors.

Disclosures: None declared.

Current address of G.K., East Africa Health Research Commission, Arusha, Tanzania.
} 
A

IL-32 $\beta$

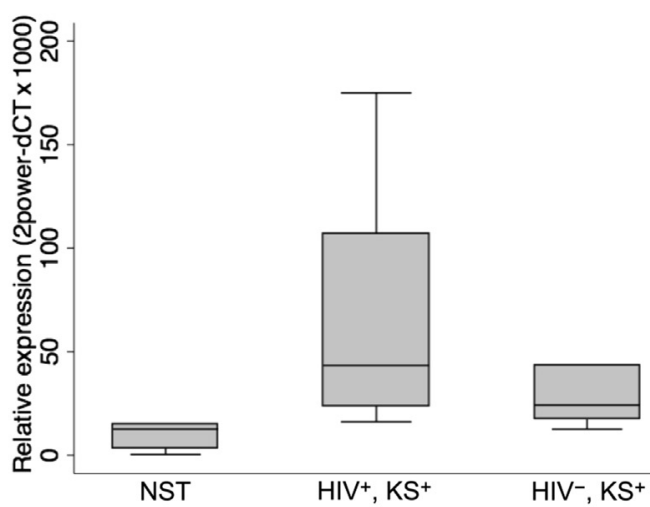

\section{B}

IL-32y

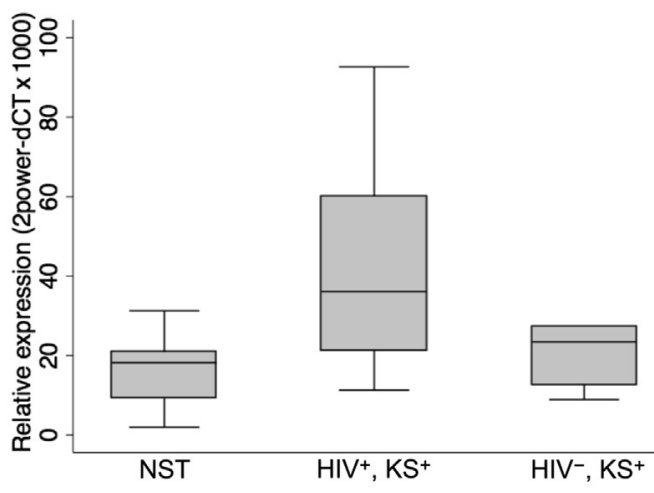

Figure 1 IL-32 isoform expression in different HIV-related $\left(\mathrm{HIV}^{+}\right)$and non-HIV-related $\left(\mathrm{HIV}^{-}\right)$Kaposi sarcoma (KS) cases compared with normal skin tissue (NST). IL-32 $\beta$ (A) and IL-32 $\gamma$ (B) mRNA relative expression in KS tumors. The results are shown as mean relative expression calculated relative to the housekeeping gene. The IL-32 $\beta$ expression in HIV-related KS is significantly elevated compared with NST ( $U$-test, two-tailed $P=0.0026)$. IL-32 $\gamma$ relative expression is also marginally significantly elevated in HIV-related KS compared with NST (U-test, two-tailed $P=0.027) . N=11 \mathrm{HIV}^{+}, \mathrm{KS}^{+}(\mathbf{A}$ and $\mathbf{B}) ; N=5 \mathrm{HIV}^{-}, \mathrm{KS}^{+}(\mathbf{A}$ and B); $N=6$ NST (A and B).

has been implicated in carcinogenesis. ${ }^{1,2}$ Carcinogenesis and inflammation are heavily intertwined processes, and the interplay between these two processes is influenced by a large array of inflammatory mediators, including IL-32. Lin and Karin, ${ }^{14}$ in 2007, described several cytokines involved in inflammatory and/or immune diseases associated with cancer development. They described the involvement of cytokines, such as TNF- $\alpha$ and IL-6. TNF- $\alpha$ was identified as the major host factor that enhances the growth of lung metastases in a mouse model, in part through activation of NF- $\kappa B$ in the tumor cells. IL-6, on the other hand, has been documented to be involved in the progression of Kaposi sarcoma (KS) ${ }^{15}$ Both of these cytokines are induced by IL-32, as previously demonstrated by Kim et al. ${ }^{7}$ This function of IL-32 illustrates its importance in carcinogenesis. KS is a multifocal tumor that manifests in four distinct epidemiological forms: AIDS-associated KS, iatrogenic KS, endemic KS, and African KS. KS-associated herpes virus (KSHV; alias human herpes virus-8) is the causative agent of
KS. ${ }^{16}$ The virus causes formation of KS spindle cells of the endothelial cell lineage; their derivation is still uncertain (ie, whether they are blood vessel or lymphatic vessel endothelial cells). ${ }^{17}$ In KS tumors, almost $80 \%$ of the KS spindle cells are infected with KSHV,${ }^{18}$ most of which are infected latently with the virus. During this latency, only a few proteins are expressed, which function primarily in maintenance of the viral genome, cellular proliferation, and activation of NF- $\mathrm{KB}$ and p38 mitogenactivated protein kinase signaling cascades. Recent studies have proposed cyclooxygenase-2 (COX-2) and its metabolite prostaglandin E2 as two pivotal proinflammatory/oncogenic molecules to play a role in the expression of major KSHV latency-associated nuclear antigen-1. ${ }^{19} \mathrm{COX}-2$, an enzyme involved in prostanoid synthesis, has been heavily associated with KSHV latent infection and, thus, KS tumor progression. ${ }^{19}$ This proangiogenic and apoptotic enzyme is up-regulated by mitogenic and inflammatory stimuli and serves to modulate the immune system in favor of KS progression. Sharma-Walia et $\mathrm{al}^{19}$ demonstrated the great potential of tumor cell death induction by specific inhibition of COX-2. Interestingly, IL-32 expression has been shown to be induced by COX-2 stimulation in cervical cancer, and it has also been recently reported to be proangiogenic. ${ }^{20,21}$ This interaction is a key factor in the mechanisms of immune evasion and progression of KS. Furthermore, KSHV is documented to express a viral IL-6 protein homologous to human IL-6. Zhang et $\mathrm{al}^{15}$ demonstrated, in their study, that blockade of this viral IL-6 has an effect on tumor progression. Both COX-2 and IL-32 are reported to influence IL-6 expression. ${ }^{19,22}$

Several studies have reported IL-32 overexpression in tumor cells compared with normal cells, indicating that IL-32 is associated with carcinogenesis. ${ }^{1,2}$ On the other hand, Oh et $\mathrm{al}^{23}$ demonstrated that IL-32 $\gamma$ inhibits tumor growth by inhibiting expression of NF-kB and STAT3. Similarly, Yun et $\mathrm{al}^{24}$ demonstrated that IL-32 $\beta$ inhibits tumor growth by increasing cytotoxic lymphocyte numbers and by inactivating the NF- $\mathrm{BB}$ and STAT3 pathways through modulation of cytokine levels in tumor tissues. These effects may be influenced by the differential role of IL-32 between cell types and its participation in different intracellular pathways, as described previously. ${ }^{10}$

We have recently demonstrated that individuals bearing the IL-32 genetic variant $r s 28372698$, which leads to increased IL-32 $\gamma$ gene expression and higher production of proinflammatory cytokines, have a higher risk for developing epithelial cell-derived thyroid carcinoma. ${ }^{3}$ Moreover, these individuals require higher dosages of radioactive iodide, the standard therapy after thyroidectomy, to achieve successful tumor remission. ${ }^{3}$

Depending on the function of the isoforms, IL-32 has thus far been demonstrated to play a critical role in both tumor progression and inhibition. It has been demonstrated to be overexpressed in tumors, with the IL-32 $\beta$ and IL- $32 \gamma$ isoforms being the most abundant. However, the mechanism behind the tumor progression has not been studied and explained. The IL-32 $\gamma$ isoform has predominantly a proapoptotic action and, thus, induces cell death. Nold et $\mathrm{al}^{6}$ 
demonstrated the potency of IL-32 to induce HIV-infected cells to undergo apoptosis after IL-32 up-regulation. They also demonstrated that on reduction of endogenous IL-32, HIV viral load tremendously increased in these cells compared with cells expressing IL-32. ${ }^{6}$ Nevertheless, contrary to this effect, tumor cells have been shown to progress and not to undergo apoptosis, even on high expression of IL-32. Splicing of the IL-32 $\gamma$ isoform into IL-32 $\beta$ has been described before to occur in THP1 cells, which was demonstrated to be relevant within the pathogenesis and severity of rheumatoid arthritis. ${ }^{11}$ These studies have revealed that the splicing from IL-32 $\gamma$ into IL-32 $\beta$ may be regarded as a safety switch because IL-32 $\beta$ is a less potent proinflammatory mediator than IL- $32 \gamma$, leading to decreased production of proinflammatory cytokines, such as IL-1 $\beta$ and IL-6. We hypothesized that this splicing mechanism of IL$32 \gamma$ to IL-32 $\beta$ is a survival mechanism that inhibits tumor cells from going into apoptosis, even with high expression of IL-32 $\gamma$. In the present study, the role of the survival mechanism that tumor cells might use to survive high expression levels of $\mathrm{IL}-32 \gamma$, which is predominantly proinflammatory and proapoptotic, was studied. The IL-32 splicing pattern in KS was studied to determine its influence on tumor progression. Furthermore, the effect of IL-6, IL-8, TNF- $\alpha$, COX-2, C-X-C chemokine receptor (CXCR) 1 , and focal adhesion kinase (FAK)-1 on tumor progression and apoptosis induction was investigated. With these experiments, we determined the possible interplay between IL32 and COX-2 and show their interaction in the initiation of tumor survival pathways in KS. Understanding these interactions may be a step forward toward development of an immune-modulating IL-32-based therapy for KS and other endothelial cell pathologies driven by chronic infections.

\section{Materials and Methods}

\section{Study Samples}

Patient tissues of HIV-infected KS cases $(N=11)$ and non-HIV-infected KS cases $(N=7)$ from patients of Dutch origin, confirmed by histology and immunohistochemistry, were selected from the database of the Department of Pathology, Radboud University Medical Center (Nijmegen, the Netherlands). These samples were selected on the basis of sample availability in the pathology department archives as well as quality and quantity of RNA obtained. Samples with poor quality and/or low RNA yield were excluded from analysis. Patients' personal details were decoded to maintain confidentiality by giving a study number to all formalinfixed, paraffin-embedded tissue biopsy specimens. Ethical approval was obtained for all patient tissues.

\section{qPCR Analysis}

Per block, five sections ( $20 \mu \mathrm{m}$ thick) were cut from formalinfixed, paraffin-embedded material under semisterile conditions and transferred to a sterile tube. RNA was isolated by lysis and RNA precipitation protocols. Tissue samples were disrupted and homogenized by an overnight incubation with Proteinase K (Qiagen, Valencia, CA). RNA extraction was performed by using RNA-Bee, according to the manufacturer's protocol (AMS Biotechnology, Abingdon, UK), including chloroform phase separation and isopropanol precipitation. Isolated RNA was subsequently transcribed into cDNA by using random hexamers (Promega, Leiden, the Netherlands), followed by real-time quantitative PCR (qPCR) using the SYBR Green method (Applied Biosystems, Foster City, CA). The following primers were used for detection: IL-32 $\alpha, 5^{\prime}$-GCTGGAGGACGACTTCAAAGA-3' (forward) and $5^{\prime}$-GGGCTCCGTAGGACTTGTCA- $3^{\prime}$ (reverse); IL-32 $\beta, \quad 5^{\prime}$-CAGTGGAGCTGGGTCATCTCA-3' (forward) and $5^{\prime}$-GGGCCTTCAGCTTCTTCATGTCATCA$3^{\prime}$ (reverse); IL-32 $\gamma, 5^{\prime}$-AGGCCCGAATGGTAATGCT-3' (forward) and 5'-CCACAGTGTCCTCAGTGTCACA-3' (reverse); TNF- $\alpha, 5^{\prime}$-GACGTGGAAGTGGCAGAAGAG-3' (forward) and $5^{\prime}$-TGCCACAAGCAGGAATGAGA-3' (reverse); IL-8, 5-AAGAGAGCTCTGTCTGGACC-3' (forward) and $5^{\prime}$-GATATTCTCTTGGCCCTTGG- $3^{\prime}$ (reverse); IL6, 5'-GGTACATCCTCGACGGCATCT-3' (forward) and $5^{\prime}$ GTGCCTCTTTGCTGCTTTCAC-3' (reverse); COX-2, 5' GGTCTGGTGCCTGGTCTGATGATG-3' (forward) and $5^{\prime}$ GTCCTTTCAAGGAGAATGGTGC-3' (reverse); CXCR1, $5^{\prime}$-CGACTGTGGGCGGATTCTTG-3' (forward) and 5'AGACCGATACCATGTGCTCT-3' (reverse); and FAK-1, $5^{\prime}$-TCCCTATGGTGAAGGAAGT-3' (forward) and $5^{\prime}$ TTCTGTGCCATCTCAATCT-3' (reverse).

Data were corrected for expression of the housekeeping gene $\beta 2$-microglobulin, for which the primers $5^{\prime}$-ATGAGTATGCCTGCCGTGTG-3' (forward) and 5'-CCAAATGCGGCATCTTCAAAC-3' (reverse) were used. Gene expression values were calculated by using the comparative threshold cycle $\left(\mathrm{C}_{\mathrm{T}}\right)$ method. The $\mathrm{C}_{\mathrm{T}}$ data for the different genes and the housekeeping gene $\beta 2$-microglobulin were used to generate $C_{T}$ values $\left(\Delta \mathrm{C}_{\mathrm{T}}=\mathrm{C}_{\mathrm{T}}\right.$ target gene $-\mathrm{C}_{\mathrm{T}}$ housekeeping gene). Thereafter, the relative quantity was calculated by $2^{\Delta \mathrm{Cr}} \times 1000$.

\section{Isolation and Stimulation of HUVECs}

Human umbilical vein endothelial cells (HUVECs) were isolated from umbilical cords from healthy donors after obtaining informed consent. Cells were cultured in RPMI 1640 medium (Gibco-Invitrogen, Gaithersburg, MD) supplemented with penicillin/streptomycin, glutamine, pyruvate, heat-inactivated pooled human serum $(10 \%)$, and heat-inactivated fetal bovine serum (10\%). HUVECs were cultured in $0.2 \% \mathrm{w} / \mathrm{v}$ gelatinized (Sigma-Aldrich, St. Louis, MO) tissue flasks/plates (Corning Inc., Corning, NY) at $37^{\circ} \mathrm{C}$ and $5 \% \mathrm{CO}_{2}$. HUVECs were stimulated with $50 \mu \mathrm{g} / \mathrm{mL}$ poly(I:C) (Invivogen, Toulouse, France) or in serum-free RPMI 1640 medium. Twenty-four hours after stimulation, total RNA was isolated by adding Tri-reagent (SigmaAldrich) to the cells and processed, as described by Heinhuis 
Table 1 The General Characteristics of the Data

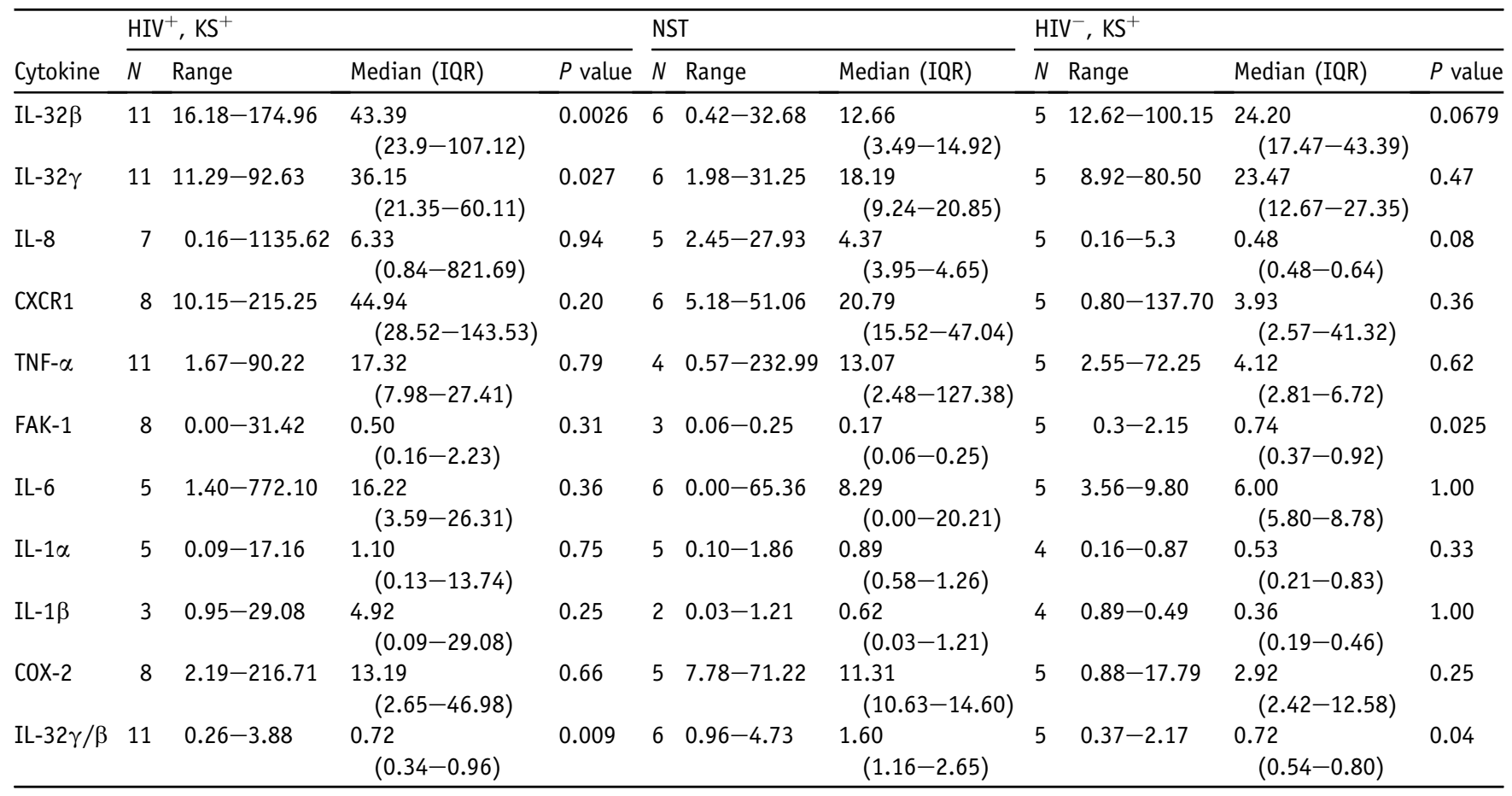

+, Present; -, absent; COX, cyclooxygenase; CXCR, C-X-C chemokine receptor; FAK, focal adhesion kinase; IQR, interquartile range; KS, Kaposi sarcoma; NST, normal skin tissue; TNF, tumor necrosis factor.

et al. ${ }^{25}$ Finally, IL-32 mRNA expression was assessed by qPCR.

\section{Immunohistochemistry}

IL-32 protein expression was evaluated by immunohistochemical staining of formalin-fixed, paraffin-embedded KS tissue sections. To remove the paraffin, tissues were incubated twice in xylene and successively in 100\%, 96\%, and $70 \%$ alcohol for 5 minutes each step. Antigens were retrieved with citrate buffer for 2 minutes in the microwave $(800 \mathrm{~W})$ and 10 minutes at room temperature citrate buffer: $\mathrm{pH}=6.0,16.4 \mathrm{~mL}$ sodium citrate $(0.1 \mathrm{~mol} / \mathrm{L})$ with $3.6 \mathrm{~mL}$ citric acid $(0.1 \mathrm{~mol} / \mathrm{L})$ in $180 \mathrm{~mL} \mathrm{H}_{2} \mathrm{O}$. The endogenous peroxidase activity was blocked with $3 \% \mathrm{H}_{2} \mathrm{O}_{2}$ in methanol for 15 minutes at room temperature. Furthermore, because tumor-like tissues contain endogenous biotin, this was blocked in the tissue sections by an avidin/biotin blocking kit, according to the manufacturer's protocol (Vector Laboratories, Burlingame, CA). Sections were incubated with $20 \%$ goat serum diluted in phosphate-buffered saline (PBS) for 10 minutes and subsequently with the first antibody (polyclonal goat anti-human IL-32 AF3040 antibody or goat polyclonal IgG isotype control AB-108-C; R\&D Systems, Minneapolis, MN), both $2.5 \mu \mathrm{g} / \mathrm{mL}$ in PBS supplemented with $5 \%$ goat serum overnight at room temperature. After washing with PBS, sections were incubated with the second antibody (rabbit anti-goat-BIOT Vector BA-5000; Vector Laboratories), 1:500 diluted in PBS supplemented with 5\% rabbit serum, for 30 minutes at room temperature. The
ABC-horseradish peroxidase complex (ABCkit-HRP Vector PK-6101; Vector Laboratories), 1:200 diluted in PBS, was applied to the sections for 30 minutes at room temperature. The substrate solution was added for 5 minutes at room temperature: $0.5 \mathrm{~mL}$ of diaminobenzidene in 9.5 mL of PBS and $10 \mu \mathrm{L}$ of $\mathrm{H}_{2} \mathrm{O}_{2}$. Tissues were counterstained with hematoxylin for 30 seconds at room temperature. Slides were dehydrated with consecutive incubation in $70 \%$, $96 \%$, and $100 \%$ alcohol and xylene (two times) for 5 minutes each step. Sections were mounted in Permount (Thermo Fisher Scientific, Waltham, MA).

\section{Statistical Analysis}

To determine significant differences between the test samples against the controls, $U$-tests were used to determine the

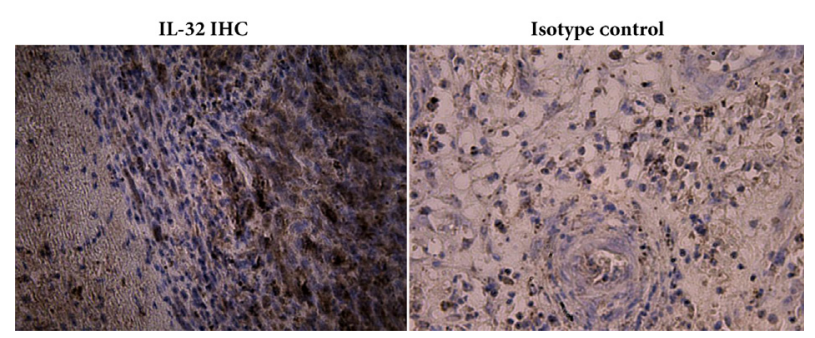

Figure 2 Micrographs of immunohistochemically stained HIV-related Kaposi sarcoma (KS) showing high IL-32 expression in HIV-related KS. HIV-related KS shows higher IL-32 protein expression using the IL32-specific monoclonal antibody (A) compared with the isotype control (B). Original magnification, $\times 40$ (A and B). IHC, immunohistochemistry. 

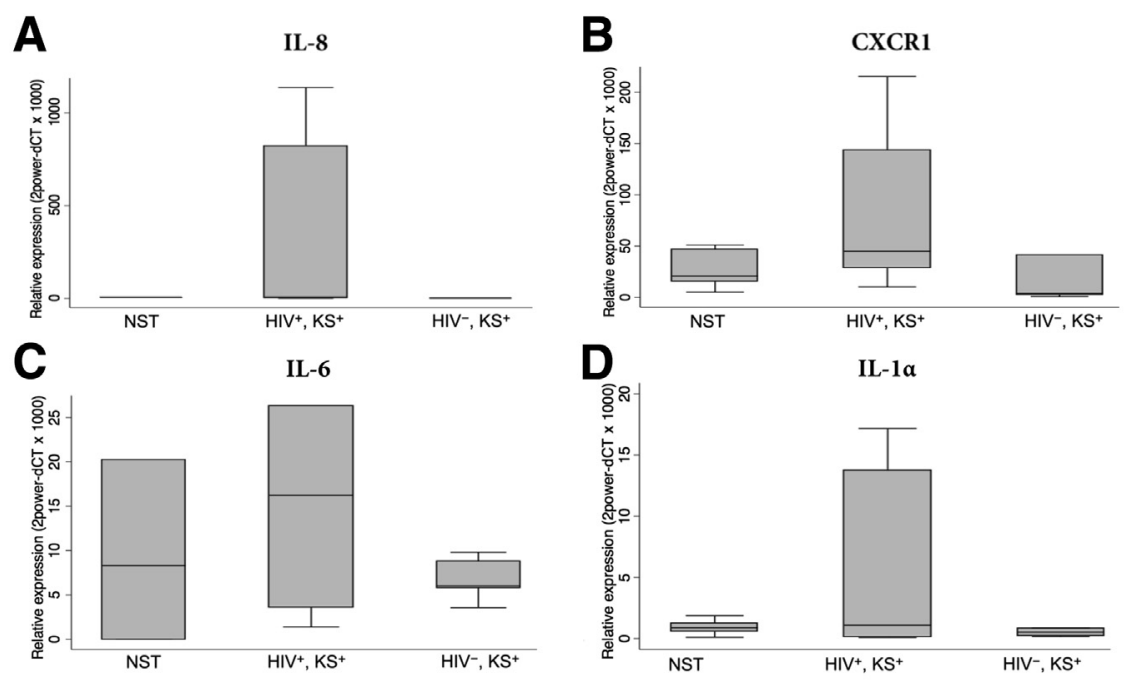

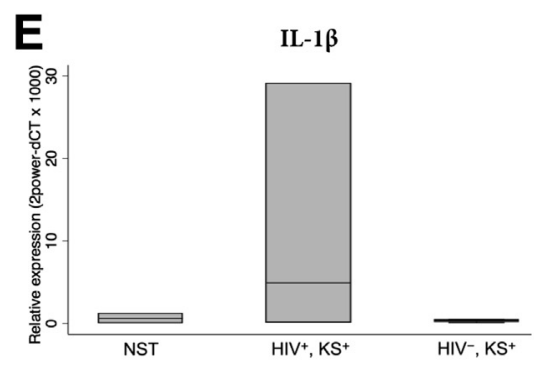

$\mathbf{F}$
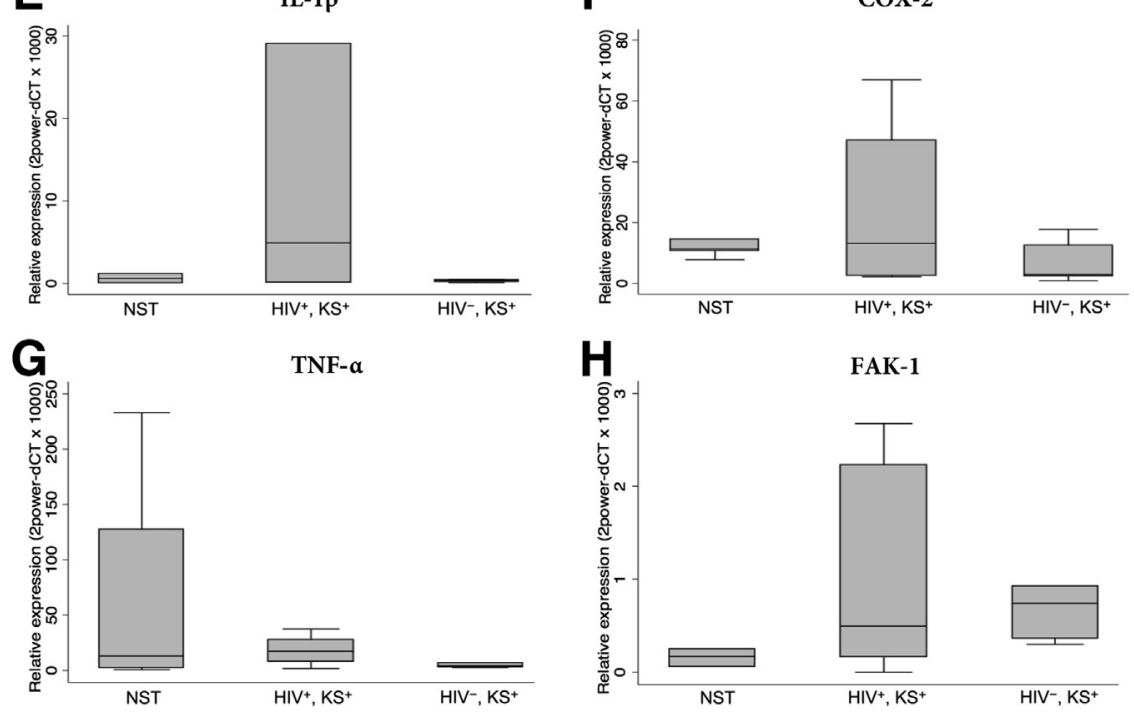

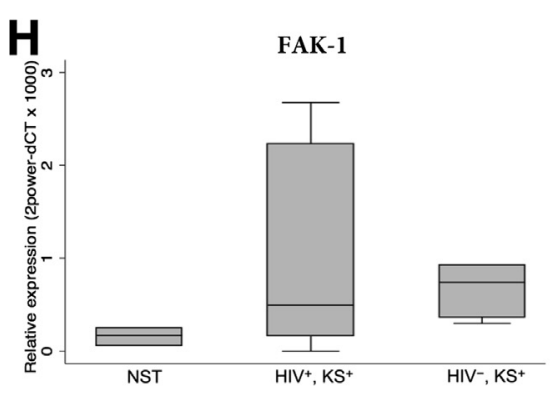

Figure 3 Relative expression of selected proinflammatory cytokines in HIV- and non-HIVrelated Kaposi sarcoma (KS). A-F: IL-8 (A), C-X-C chemokine receptor (CXCR) 1 (B), IL-6 (C), IL-1 $\alpha$ (D), IL-1ß (E), and cyclooxygenase (COX)-2 (F) mRNA relative expression shows higher expression in HIV-related KS compared with normal skin tissue (NST). G: Tumor necrosis factor (TNF)- $\alpha$ shows lower expression in both HIV- and non-HIVrelated KS compared with NST. H: Focal adhesion kinase (FAK)-1 shows significantly increased expression in non-HIV-related KS compared with NST ( $U$-test, $P=0.025) . A: N=7 \mathrm{HIV}+, \mathrm{KS}+$; $N=5 \mathrm{HIV}-, \mathrm{KS}+; N=5 \mathrm{NST}$. B: $N=8 \mathrm{HIV}+, \mathrm{KS}+;$ $N=5 \mathrm{HIV}-, \mathrm{KS}+; N=7 \mathrm{NST}$; C: $N=5 \mathrm{HIV}+, \mathrm{KS}+$; $N=5 \mathrm{HIV}-, \mathrm{KS}+; N=7 \mathrm{NST} ; \mathrm{D}: N=5 \mathrm{HIV}+, \mathrm{KS}+;$ $N=4 \mathrm{HIV}-, \mathrm{KS}+; N=6 \mathrm{NST} ; \mathrm{E}: N=3 \mathrm{HIV}+, \mathrm{KS}+;$ $N=4 \mathrm{HIV}-, \mathrm{KS}+; N=3 \mathrm{NST} ; \mathrm{F}: N=8 \mathrm{HIV}+, \mathrm{KS}+$; $N=5 \mathrm{HIV}-, \mathrm{KS}+; N=5 \mathrm{NST} ; \mathrm{G}: N=11$ $\mathrm{HIV}+, \mathrm{KS}+; N=5$ HIV-,KS+; $N=4 \mathrm{NST} ; \mathrm{H}$ : $N=8 \mathrm{HIV}+, \mathrm{KS}+; N=5 \mathrm{HIV}-, \mathrm{KS}+; N=4 \mathrm{NST}$. two-tailed $P$ values. To account for the comparisons of normal skin tissue (NST) versus $\mathrm{HIV}^{+} \mathrm{KS}^{+}$and NST versus $\mathrm{HIV}^{-} \mathrm{KS}^{+}$, a two-tailed $P<0.025$ was considered statistically significant. The analyses were performed using GraphPad Prism version 5 (GraphPad Software, Inc., La Jolla, CA).

\section{Results}

\section{General Characteristics of the Data}

The general characteristics of the data are listed in Table 1.

\section{IL-32 $\beta$ and IL-32 $\gamma$ Isoform mRNA Is Abundantly Expressed in KS}

To investigate whether IL-32 is expressed in KS, qPCR was used. Expression of IL-32 isoforms was observed in $\mathrm{KS}$ cases (Figure 1), with abundant quantities of IL-32 $\beta$ and
IL-32 $\gamma$ isoforms in particular. IL-32 $\alpha$ was not detected in KS and NST (data not shown). IL-32 $\beta$ showed significantly elevated expression levels in HIV-related KS patients compared with NST (Figure 1A). HIV-related KS cases also showed marginally statistically significant high levels of IL-32 $\gamma$ compared with normal skin controls (Figure 1B).

\section{IL-32 Protein Quantities Are More Abundant in HIV-Related KS}

To assess IL-32 protein levels, immunohistochemical staining was performed for IL-32 in HIV-related KS. Cases with the highest and lowest levels of IL-32 mRNA were selected. High IL-32 protein expression was observed in HIV-related KS compared with isotype control. Corresponding high levels of IL-32 protein were detected in high IL-32 mRNA expressing tissues. Also, hematoxylin and eosin staining of HIV-related $\mathrm{KS}$ and non-HIV-related KS was performed, and the degree 
A

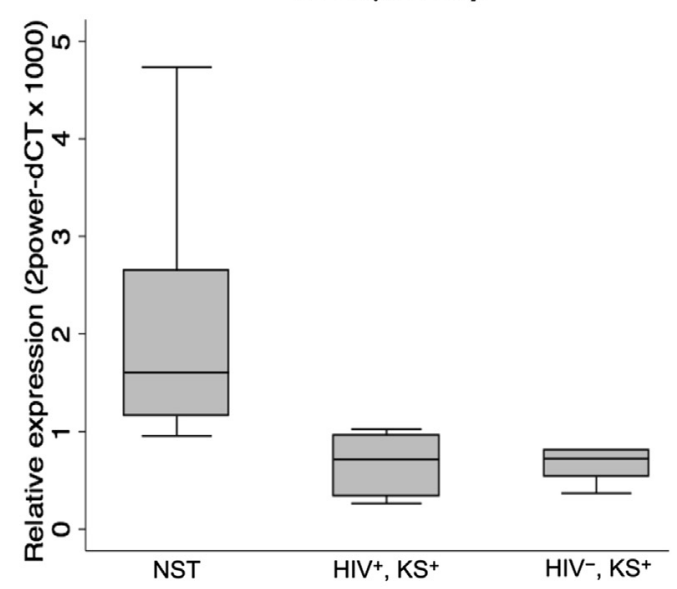

B

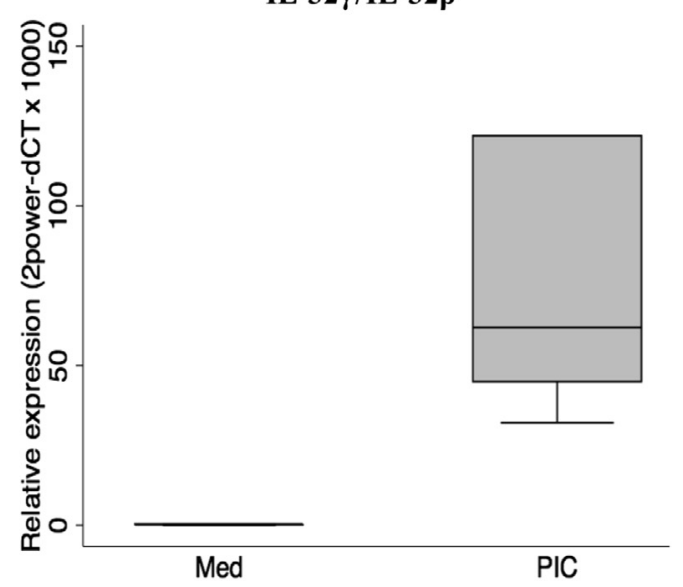

Figure $4 \mathrm{IL}-32 \gamma / \mathrm{IL}-32 \beta$ splicing ratio in HIV- and non-HIV-related Kaposi sarcoma (KS) and normal skin tissue (NST; A) and in medium control (Med) and poly(I:C) (PIC; B). The splicing ratio was calculated by dividing the relative expressions of the different IL-32 isoforms. The IL-32 $\gamma / \mathrm{IL}-32 \beta$ ratio is significantly reduced in HIV KS compared with NST (A) (U-test, twotailed $P=0.009$ ) and significantly increased in PIC-stimulated human umbilical vein endothelial cells (HUVECs) compared with untreated HUVECs in medium control (B) ( $U$-test, two-tailed $P=0.0012) . N=11 \mathrm{HIV}^{+}, \mathrm{KS}^{+}$ (A); $N=5 \mathrm{HIV}^{-}, \mathrm{KS}^{+}(\mathbf{A}) ; N=6 \mathrm{NST}(\mathbf{A}) ; N=4$ poly(I:C) treated (B); $N=8$ medium control (B).

of inflammation in the same cases was assessed. More cellularity and increased numbers of lymphocytes and plasma cells were observed in non-HIV KS (Figure 2).

\section{IL-8, CXCR1, IL-6, IL-1 $\alpha$, IL-1 $\beta$, and COX-2 Relative Expression Levels Are Moderately Elevated in HIV- Related KS, whereas TNF- $\alpha$ and FAK-1 Are Moderately Down-Regulated}

To investigate the role of other selected proinflammatory cytokines and mediators in the tumor progression and to test our hypothesis of COX-2 and IL-8 involvement, the mRNA expression levels of these cytokines were determined by qPCR. FAK-1 (Figure 3H) showed significantly increased expression in non-HIV-related KS compared with NST. IL-8 (Figure 3A), CXCR1 (Figure 3B), IL-6 (Figure 3C), IL-1 $\alpha$ (Figure 3D), IL-1 $\beta$ (Figure 3E), and COX-2 (Figure 3F) showed higher expression in HIV-related KS compared with non-HIV-related KS and NST. TNF- $\alpha$ (Figure 3G) showed lower expression in HIV- and nonHIV-related KS compared with NST.

\section{IL-32 Splicing in KS}

To investigate the relative expression of IL-32 in KS compared with normal expression in uninfected skin tissue and virus-infected epithelial cells, qPCR was conducted on poly(I:C) stimulated HUVECs. To investigate the relative quantities of the different IL-32 isoforms, the ratio of IL$32 \gamma / \mathrm{IL}-32 \beta$ was calculated. The IL-32 $\gamma / \mathrm{IL}-32 \beta$ (Figure 4B) ratio was statistically significantly increased in HUVECs stimulated with poly(I:C) compared with medium control. The splicing ratio in HIV-related $\mathrm{KS}$ was significantly reduced compared with NST (Figure 4A).

\section{IL-32 Carcinogenesis Model}

We propose IL-32 plays a role in carcinogenesis through the induction of IL-8 production. IL-8 is then excreted to the extracellular environment, where it interacts with its receptor CXCR1 and initiates the IL-8 signaling pathway, which occurs through FAK-1 as its downstream signaling molecule. In turn, this signaling pathway of IL-8 plays a role in tumor survival by production of cell survival proteins. KS seems to be using this mechanism, because increased IL-32 $\gamma$, IL-32 $\beta$, IL-8, CXCR1, and FAK-1 expression was observed. Interestingly, KS showed a decreased IL-32 $\gamma / \mathrm{IL}-32 \beta$ splicing ratio compared with NST, whereas poly(I:C) stimulated HUVECs showed an increased IL-32 $\gamma / \mathrm{IL}-32 \beta$ splicing ratio. This observation is interesting and indicates that human herpes virus8 -induced KS behaves differently from other viral infectious agents, which usually lead to increased IL-32 $\gamma /$ IL-32 $\beta$ splicing ratios. We propose IL-32 plays a role in carcinogenesis through the splicing of the proapoptotic IL- $32 \gamma$ isoform to its lesser potent isoform IL-32 $\beta$ and eventually to the IL-32 $\alpha$ isoform. We propose that this splicing mechanism plays an important role in the balance between apoptosis and survival among other mechanisms. The model in Figure 5 shows the interaction between IL-32 and IL-8. Furthermore, the key mechanisms and mediators that play a role in the balance between apoptosis and cell survival with respect to IL-32 involvement are shown.

\section{Discussion}

In this study, elevated expression of IL-32 $\gamma$ and IL-32 $\beta$ isoforms was observed in HIV-related KS cases. The current data show that IL-32 $\gamma$ and IL-32 $\beta$ isoforms are significantly 


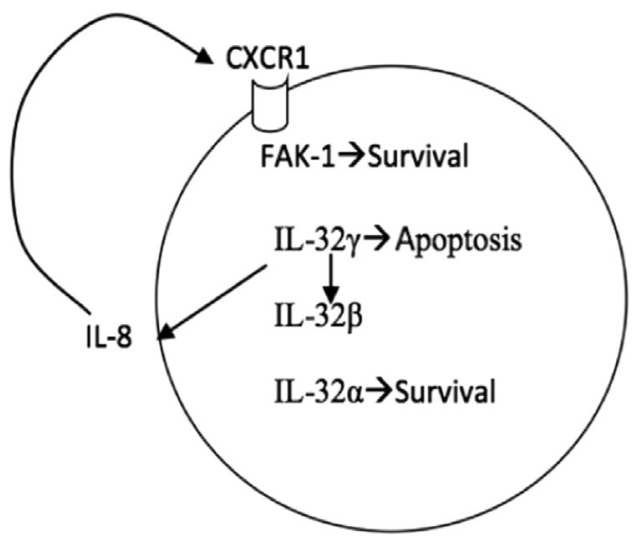

Figure 5 A proposed model of the interaction of IL-32 and IL-8 signaling in the progression of tumors and the key mechanisms and mediators to the balance between apoptosis (elevated IL-32 $\gamma$ and elevated IL$32 \beta)$ and cell survival [elevated IL-8 signaling, IL-32 $\gamma$ to IL-32 $\alpha$ splicing, and elevated $\mathrm{C}-\mathrm{X}-\mathrm{C}$ chemokine receptor (CXCR) 1 and focal adhesion kinase (FAK)-1] with respect to IL-32.

elevated in HIV-related KS. This trend has been observed in other tumors by other investigators as well ${ }^{2,23}$ and is further supported by the present study. In addition to this observation, our data also show the occurrence of splicing activity, especially from IL-32 $\gamma$ to IL-32 $\beta$. Heinhuis et $\mathrm{al}^{26}$ demonstrated, in a human embryonic kidney cell line, that cells undergo apoptosis on transiently elevated expression of IL-32 $\gamma$ and IL-32 $\beta$. In addition to that, Goda et $\mathrm{al}^{27}$ indicated that IL-32 may be involved in activation-induced cell death in T cells. However, the KS tumor cells do not undergo apoptosis, even with elevated expression of these proapoptotic and proinflammatory IL-32 isoforms demonstrated to induce cell death. We, thus, speculate that an additional pathway is favored by the proapoptotic and proinflammatory microenvironment. A possible role for IL8 in this survival mechanism was observed that may be used by these tumor cells to progress in an IL-32 $\gamma$ and IL-32 $\beta$ environment. We speculate that KS tumor cells, despite having high IL-32 $\gamma$ to IL-32 $\beta$ splicing activity and, thus, high expression of IL-32 $\gamma$ and IL-32 $\beta$ isoforms, can survive by up-regulating IL- 8 and CXCR 1 expression. This serves as the survival mechanism by increasing FAK-1 expression and, thus, triggers cell survival mechanisms. The induction of IL-8 production by IL-32 expression has been demonstrated before by other investigators. ${ }^{7}$

HIV-related KS cases showed significantly elevated expression of IL-32 $\beta$ and IL-32 $\gamma$ compared with NST. This observation fits well with findings in other tumor types, as discussed in the first paragraph. The elevated levels of the proapoptotic and proinflammatory IL-32 isoforms in HIVand non-HIV-related KS tumors may be explained by the fact that KSHV-8 is involved with or without HIV, respectively. These KSHV-8 viruses induce inflammation through immune activation. This leads to increased production of proinflammatory cytokines, including IL-32 $\gamma$ and IL-32 $\beta$. Nold et $\mathrm{al}^{6}$ demonstrated mechanistically the antiviral effect of IL-32 toward HIV-1 and proposed that IL32 is a natural inhibitor of the virus. The KSHV-8 virus, on the other hand, uses viral IL-6, a viral analog of human IL-6, which is induced by IL-32 to stimulate cells and, thus, bind to gp130, contributing to the pathogenic processes involved. ${ }^{15}$ HIV-related KS tumors were observed to exhibit a significantly higher IL-32 $\gamma$ to IL-32 $\beta$ splicing activity. This splicing activity was much more efficient than in NST. Furthermore, HIV-related KS showed a trend toward increased expression of IL- $1 \alpha$, IL-1 $\beta$, IL-8, IL-6, CXCR1, and COX-2. Taken together, these observations suggest KS as an efficient tumor in using the two proposed survival mechanisms. These data further indicate that tumor cells may use splicing activity of IL-32 $\gamma$ to IL-32 $\beta$ and upregulation of IL- 8 and IL- 6 signaling. This leads us to further speculate on the involvement of IL-8 and IL-6 signaling in the survival mechanism of tumor cells, thus favoring tumor progression. TNF- $\alpha$ and FAK- 1 also showed a tendency of decreased expression in HIV-related KS compared with NST and non-HIV-related KS. This tendency is worth exploring further. We can speculate the tendency to be because of the initial levels of IL- $32 \gamma$ and IL-32 $\beta$. The high splicing activity of IL-32 $\gamma$ to IL-32 $\beta$ in HIV-related KS may explain the decreased tendency of TNF- $\alpha$ expression compared with non-HIV-related KS and NST because the IL-32 $\beta$ isoform is a less potent proinflammatory cytokine compared with the IL-32 $\gamma$ isoform.

The current study has several limitations, mainly the lack of cell culture experiments using KS cell lines to explicitly study the proposed mechanisms separately. Nevertheless, this is the first study, to our knowledge, to explore these pathways in KS tumor progression.

In conclusion, our findings bring into perspective key matters regarding KS tumor cell survival. HIV- and nonHIV-related KS tumors show efficient IL-32 $\gamma$ to IL-32 $\beta$ splicing activity compared with NST. We speculate that the splicing of IL-32 $\gamma$ to IL-32 $\beta$ serves as one of the survival mechanisms used by KS cells. Furthermore, the trend toward increased IL-8, IL-6, IL-1 $\alpha$, IL-1 $\beta$, CXCR1, and COX-2 expression also seems to be following the same trend of being most evident in KS. We propose further studies into these novel pathways of elevated IL-8 signaling and IL-32 splicing that tumor cells may be using for their survival, because these findings may serve as an important cornerstone for cancer therapy in the future.

\section{References}

1. Nishida A, Andoh A, Inatomi O, Fujiyama Y: Interleukin-32 expression in the pancreas. J Biol Chem 2009, 284:17868-17876

2. Seo EH, Kang J, Kim KH, Cho MC, Lee S, Kim HJ, Kim JH, Kim EJ, Park DK, Kim SH, Choi YK, Kim JM, Hong JT, Yoon DY: Detection of expressed IL-32 in human stomach cancer using ELISA and immunostaining. J Microbiol Biotechnol 2008, 18:1606-1612

3. Plantinga TS, Costantini I, Heinhuis B, Huijbers A, Semango G, Kusters B, Netea MG, Hermus AR, Smit JW, Dinarello CA, Joosten LA, Netea-Maier RT: A promoter polymorphism in human 
interleukin-32 modulates its expression and influences the risk and the outcome of epithelial cell-derived thyroid carcinoma. Carcinogenesis 2013, 34:1529-1535

4. Dinarello CA, Kim SH: IL-32, a novel cytokine with a possible role in disease. Ann Rheum Dis 2006, 65 Suppl 3:iii61-iii64

5. Netea MG, Azam T, Lewis EC, Joosten LA, Wang M, Langenberg D, Meng X, Chan ED, Yoon DY, Ottenhoff T, Kim SH, Dinarello CA: Mycobacterium tuberculosis induces interleukin-32 production through a caspase-1/IL-18/interferon-gamma-dependent mechanism. PLoS Med 2006, 3:e277

6. Nold MF, Nold-Petry CA, Pott GB, Zepp JA, Saavedra MT, Kim SH, Dinarello CA: Endogenous IL-32 controls cytokine and HIV-1 production. J Immunol 2008, 181:557-565

7. Kim SH, Han SY, Azam T, Yoon DY, Dinarello CA: Interleukin-32: a cytokine and inducer of TNFalpha. Immunity 2005, 22:131-142

8. Nold-Petry CA, Nold MF, Zepp JA, Kim SH, Voelkel NF, Dinarello CA: IL-32-dependent effects of IL-1beta on endothelial cell functions. Proc Natl Acad Sci U S A 2009, 106:3883-3888

9. Heinhuis B, Popa CD, van Tits BL, Kim SH, Zeeuwen PL, van den Berg WB, van der Meer JW, van der Vliet JA, Stalenhoef AF, Dinarello CA, Netea MG, Joosten LA: Towards a role of interleukin32 in atherosclerosis. Cytokine 2013, 64:433-440

10. Joosten LA, Heinhuis B, Netea MG, Dinarello CA: Novel insights into the biology of interleukin-32. Cell Mol Life Sci 2013, 70:3883-3892

11. Heinhuis B, Koenders MI, van de Loo FA, Netea MG, van den Berg WB, Joosten LA: Inflammation-dependent secretion and splicing of IL-32 \{gamma\} in rheumatoid arthritis. Proc Natl Acad Sci U S A 2011, 108:4962-4967

12. Joosten LA, Netea MG, Kim SH, Yoon DY, Oppers-Walgreen B, Radstake TR, Barrera P, van de Loo FA, Dinarello CA, van den Berg WB: IL-32, a proinflammatory cytokine in rheumatoid arthritis. Proc Natl Acad Sci U S A 2006, 103:3298-3303

13. Calabrese F, Baraldo S, Bazzan E, Lunardi F, Rea F, Maestrelli P, Turato G, Lokar-Oliani K, Papi A, Zuin R, Sfriso P, Balestro E, Dinarello CA, Saetta M: IL-32, a novel proinflammatory cytokine in chronic obstructive pulmonary disease. Am J Respir Crit Care Med 2008, 178:894-901

14. Lin WW, Karin M: A cytokine-mediated link between innate immunity, inflammation, and cancer. J Clin Invest 2007, 117:1175-1183

15. Zhang YJ, Bonaparte RS, Patel D, Stein DA, Iversen PL: Blockade of viral interleukin-6 expression of Kaposi's sarcoma-associated herpesvirus. Mol Cancer Ther 2008, 7:712-720

16. Chang Y, Cesarman E, Pessin MS, Lee F, Culpepper J, Knowles DM, Moore PS: Identification of herpesvirus-like DNA sequences in AIDSassociated Kaposi's sarcoma. Science 1994, 266:1865-1869

17. Sturzl M, Zietz C, Monini P, Ensoli B: Human herpesvirus-8 and Kaposi's sarcoma: relationship with the multistep concept of tumorigenesis. Adv Cancer Res 2001, 81:125-159
18. Sturzl M, Blasig C, Schreier A, Neipel F, Hohenadl C, Cornali E, Ascherl G, Esser S, Brockmeyer NH, Ekman M, Kaaya EE, Tschachler E, Biberfeld P: Expression of HHV-8 latency-associated T0.7 RNA in spindle cells and endothelial cells of AIDS-associated, classical and African Kaposi's sarcoma. Int J Cancer 1997, 72: $68-71$

19. Sharma-Walia N, Paul AG, Bottero V, Sadagopan S, Veettil MV, Kerur N, Chandran B: Kaposi's sarcoma associated herpes virus (KSHV) induced COX-2: a key factor in latency, inflammation, angiogenesis, cell survival and invasion. PLoS Pathog 2010, 6: e1000777

20. Lee S, Kim JH, Kim H, Kang JW, Kim SH, Yang Y, Kim J, Park J, Park S, Hong J, Yoon DY: Activation of the interleukin-32 pro-inflammatory pathway in response to human papillomavirus infection and over-expression of interleukin-32 controls the expression of the human papillomavirus oncogene. Immunology 2011, 132:410-420

21. Nold-Petry CA, Rudloff I, Baumer Y, Ruvo M, Marasco D, Botti P, Farkas L, Cho SX, Zepp JA, Azam T, Dinkel H, Palmer BE, Boisvert WA, Cool CD, Taraseviciene-Stewart L, Heinhuis B, Joosten LA, Dinarello CA, Voelkel NF, Nold MF: IL-32 promotes angiogenesis. J Immunol 2014, 192:589-602

22. Jung MY, Son MH, Kim SH, Cho D, Kim TS: IL-32gamma induces the maturation of dendritic cells with Th1- and Th17-polarizing ability through enhanced IL-12 and IL-6 production. J Immunol 2011, 186: 6848-6859

23. Oh JH, Cho MC, Kim JH, Lee SY, Kim HJ, Park ES, Ban JO, Kang JW, Lee DH, Shim JH, Han SB, Moon DC, Park YH, Yu DY, Kim JM, Kim SH, Yoon DY, Hong JT: IL-32gamma inhibits cancer cell growth through inactivation of NF-kappaB and STAT3 signals. Oncogene 2011, 30:3345-3359

24. Yun HM, Oh JH, Shim JH, Ban JO, Park KR, Kim JH, Lee DH, Kang JW, Park YH, Yu D, Kim Y, Han SB, Yoon DY, Hong JT: Antitumor activity of IL-32beta through the activation of lymphocytes, and the inactivation of NF-kappaB and STAT3 signals. Cell Death Dis 2013, 4:e640

25. Heinhuis B, Koenders MI, van de Loo FA, van Lent PL, Kim SH, Dinarello CA, Joosten LA, van den Berg WB: IL-32gamma and Streptococcus pyogenes cell wall fragments synergise for IL-1dependent destructive arthritis via upregulation of TLR-2 and NOD2. Ann Rheum Dis 2010, 69:1866-1872

26. Heinhuis B, Koenders MI, van den Berg WB, Netea MG, Dinarello CA, Joosten LA: Interleukin 32 (IL-32) contains a typical alpha-helix bundle structure that resembles focal adhesion targeting region of focal adhesion kinase-1. J Biol Chem 2012, 287:5733-5743

27. Goda C, Kanaji T, Kanaji S, Tanaka G, Arima K, Ohno S, Izuhara K: Involvement of IL-32 in activation-induced cell death in T cells. Int Immunol 2006, 18:233-240 